\title{
Innovations through the Supply Chain and Increased Production: The Case of Aquaculture
}

\author{
Frank Asche ${ }^{1}$, Kristin H. Roll ${ }^{1}$, and Ragnar Tveteras ${ }^{2}$ \\ ${ }^{1}$ Department of Industrial Economics, University of Stavanger, N-4036 Stavanger, Norway \\ ${ }^{2}$ Stavanger Centre for Innovation Research, \\ University of Stavanger, N-4036 Stavanger, Norway \\ \{Frank. Asche, Kristin.H.Roll, Ragnar.Tveteras\}@uis.no
}

\begin{abstract}
During the last decades, aquaculture has been the world's fastest growing food production technology. This is primarily due to the fact that control with the production process has allowed innovations thorough the supply chain, leading to increased demand and thereby increased production. We investigate this process for three leading species; salmon, sea bass and shrimp. The process has been very different for the three species. Sea bass show that despite impressive performance on the cost side, production growth in an industry that is not able to create demand growth will be limited. Shrimp show that as soon as innovation and productivity growth upstream is hindered, production growth will also be limited. Salmon has achieved a better balance between upstream and downstream innovations, and has had a smoother increase in production.
\end{abstract}

Keywords: Aquaculture, innovation, increased production.

\section{Introduction}

During recent decades, aquaculture has been the world's fastest growing food production technology, creating a blue revolution [1,2]. Salmon and sea bass are leading species in Europe, and salmon and shrimp as the globally leading species $[3,4]$. Innovations leading to productivity growth and demand growth are the main forces driving this process. The effect of technological and market innovations as well as productivity growth is well understood, as control with the production process enables innovations that increase productivity, reduce production cost and increase competitiveness [4]. This makes it profitable to increase production despite of declining prices, and transfer a significant share of the productivity growth to the consumers in the form of lower prices [3].

While we have a good understanding of the effect of productivity growth, less is known about product development and demand growth in product as well as geographical space. [5] note that species where the price development indicates a substantial productivity growth will have limited production growth if there is no demand growth. Sea bass in the Mediterranean is an example of a species where the price decline has been as rapid as for salmon, but where production growth is less 
than a tenth of the growth for salmon. [4] highlights the importance of demand side innovations as more efficient logistics, and use salmon and shrimp as examples of species where these have been important driving factors.

In this paper we will study the interaction between demand growth and production growth for different aquaculture species; salmon, shrimp and sea bass. These species are characterized by a substantial productivity growth leading to a significant reduction in production cost. However, the production expands much more rapidly for salmon and shrimp than for sea bass and sea bream. This difference is primarily caused by the different demand growth. We will use salmon as our base case, as this is the species which most data is available for, and the insights will then be applied to the other species.

\section{Aquaculture}

While aquaculture is an old production technology, it was not very important in terms of quantity produced until the 1970s. Then, a significant change took place as better control of the production process enabled a number of new technologies and production practices to be developed and implemented. This improved the competitiveness of aquaculture products both as a source of basic food and as a cash crop. The competitiveness of aquaculture has further been increased by the product development and marketing that was possible with a more predictable supply. The combined effect of productivity and demand growth has made aquaculture the world's fastest growing animal-based food sector in recent decades [2].

Since 1970, aquaculture production has grown from being an insignificant source of seafood to an important provider of protein for human consumption. In 1970, aquaculture production was still rather miniscule with a produced quantity of about 3.5 million metric tons, representing 5.1 percent of total seafood supply. In 2008, aquaculture accounted for about 40 percent of total seafood supply with a production of 58 million metric tons. Fisheries production, on the other hand, has fluctuated between 90 and 100 million metric tons in annual landings, with no particular trend. The increased production in aquaculture is accordingly the only reason why global seafood supply has continued to increase since 1990. Moreover, the increased production has been sufficient to not only maintain but also to slightly increase global per capita consumption of seafood.

\section{Salmon}

We will start by looking more closely at salmon, because this is one of the species with the most data available. Most of the data used her will be taken from or be extensions of [3]. For any product, the production volume over time is determined by the producers' profitability, with production tending to increase if it is very profitable. On the other hand, production will decrease if other uses of capital and labor are more profitable and if producers are losing money. A decline in the price of salmon (and other aquaculture species) has been necessary to induce greater consumption of the product. For this to be profitable, production costs must also have been substantially 
reduced. This has indeed been the case [6-9], as production cost has followed the price. The main factors behind reduced production costs are productivity growth and technological change.

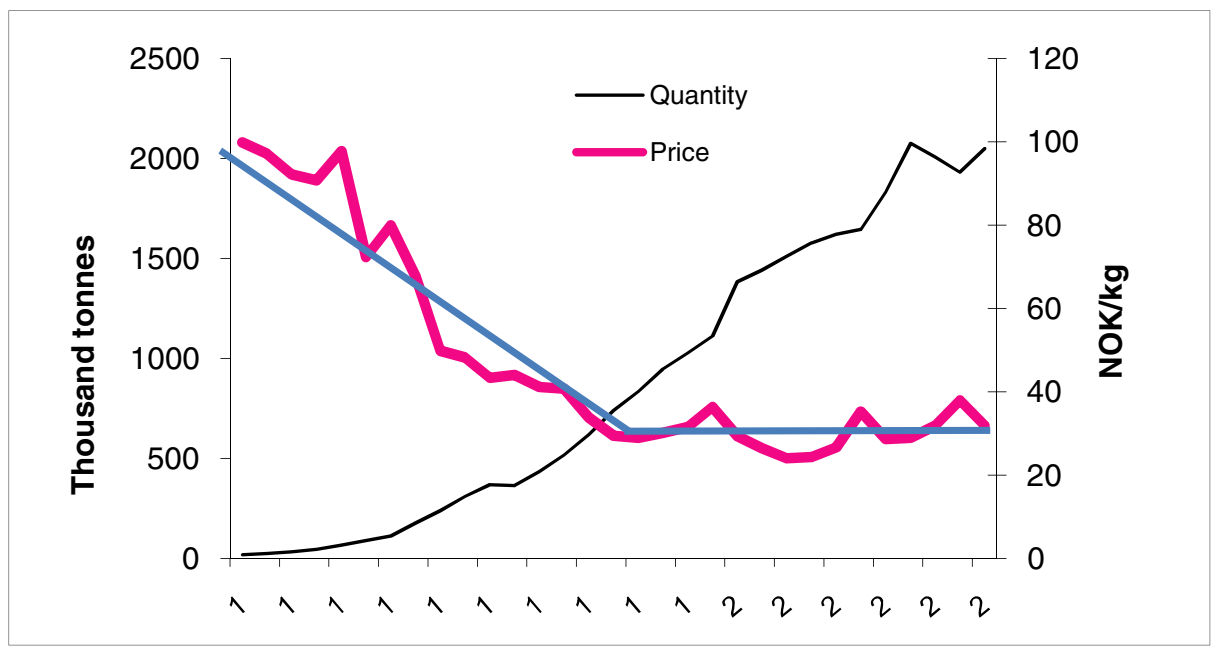

Fig. 1. Real export price and production cost for farmed Atlantic salmon, 1985-2011

Figure 1 shows real production cost and export price for salmon in Norway. Both variables have a clear downward trend, and the gap between them is consistently small. The average price in 2011 was about a quarter of the price in 1985, and the reduction in production cost was of the same magnitude. The important message here is that there is a close relationship between the development of productivity and falling export prices. Productivity gains are therefore able to explain a great deal of the decline in farmed salmon prices, as the price has been moving down with the production cost, keeping the profit margin relatively constant. This is also to be expected in a competitive industry, since high profitability is the market's signal to increase production. As the cost reduction has been translated into lower prices, it is also clear that the productivity gains have been passed on to consumers. The main effect for the producers is that they become larger and hence earn a higher profit due to the larger quantities produced.

The reduction in production costs is due to two main factors. First, fish farmers have become more efficient, so they produce more salmon with the same input. This is normally referred to as the fish farmers' productivity growth. Second, improved input factors (e.g., better feed and feeding technology and improved genetic attributes due to salmon breeding) make the production process less costly. This is due to technological change for fish farmers and productivity growth for the fish farm suppliers. This distinction is often missed, and the productivity growth for the farmers, as well as for their suppliers, is somewhat imprecisely referred to as productivity growth for the whole industry. In addition, while the focus is on the production process, productivity gains in the distribution chain to the retail outlet are equally important. 


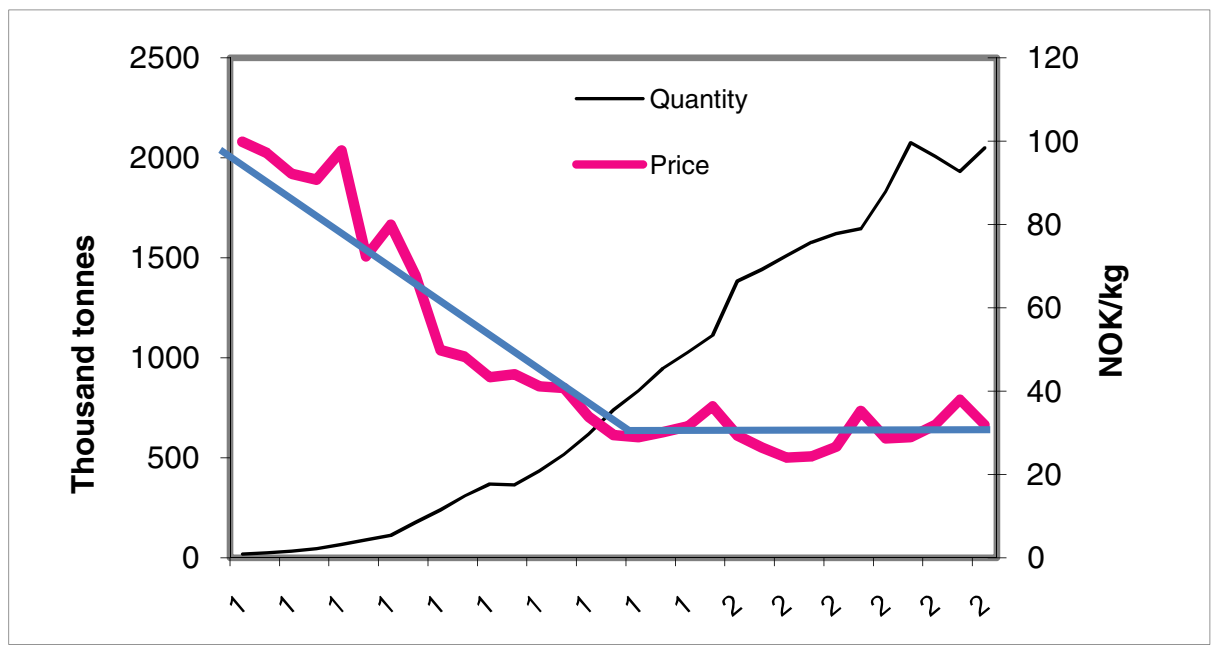

Fig. 2. Real Norwegian export price global production of farmed Atlantic salmon

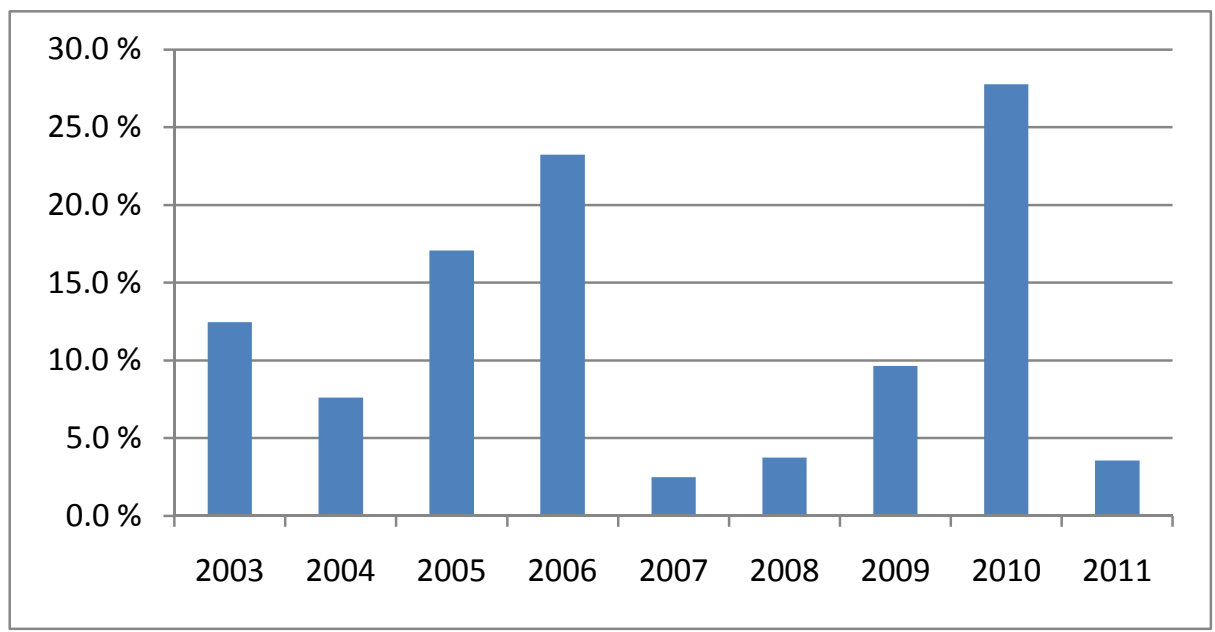

Fig. 3. Global demand growth for farmed Atlantic salmon, 2002-2011

As productivity and demand growth both constitute important factors in this market, it is an excellent market to study the impact of demand growth. To support this argument, Figure 2 shows aggregate production of Atlantic salmon together with the real Norwegian export price. The trend line shows that up to the mid-1990s, productivity growth clearly outpaced demand growth resulting in a significant downward shift in the real price. However, from the mid-1990s onward, the real price has been relatively stable indicating that demand growth has kept pace with productivity growth. With the continued increase in salmon production, this suggests substantial demand growth. [10] shows that the demand growth for salmon in France 
is $4.7 \%$ and for the EU it is $7.6 \%$ for the period 1996 to 2009 . As production has been growing at a higher rate, this suggests that demand growth has been faster outside of Europe. Using the same approach [11] and a demand elasticity of -1.1 for data covering the world for the period 2003-2011 we find that this is the case as the average annual demand growth is $11.9 \%$. However, as shown in figure 3 , and as found by [10] for Europe, it is highly variable. This match the production growth for the period well, although the cyclicality in the prices (figure 2) and the demand growth (figure 3) indicates that the process is anything but smooth and leads to substantial volatility in profitability. This indicates that supply side explanations are not the only cause for price volatility [12], and that the demand side can have contributed to the increased price volatility observed by [13].

The market has expanded in two dimensions; geographical space and product space. Early on, the geographical space was most important, as the two main product forms, whole fresh salmon and smoked sides of salmon was introduced in new markets. This process was facilitated by a number of innovations in logistics, distribution and transports. Of particular importance was the use of truck-lines in Europe that allowed fresh salmon to be in the fish counter anywhere in Western Europe less than three days after it was out of the sea. This turned local fresh fish markets into a regional European markets. In the mid 1980s one also created the infrastructure to allow large scale air transport of salmon, linking first the USA and then Japan to the European salmon market, and then enabling Chile to become a major producer. From the mid 1990s the salmon market has been global, as Chile and Norway, ship salmon to more than 160 countries. However, the real revolution has taken place in product space, as salmon is now sold in hundreds of product forms, and the food processing allows salmon to reach new consumers by introducing new product forms every year. This development has occurred because food processors has found that salmon is a competitive input that can be sold not only in new types of cuts that develops the traditional product, but also in ready-to-eat packages and other product forms away from the fish counter.

\section{Sea Bass}

After salmon, sea bass is the most successful farmed fish in Europe. Farmed production started to grow in the late 1980s, and passed 1,000 tonnes in 1987. In 2008 about 116,000 tonnes sea bream was produced, and a quantity of a similar magnitude was also produced of sea bream under similar conditions. As shown in Figure 4, superficially the development looks very similar to salmon and shrimp with a strong production growth and a rapidly declining price. The price has declined at a similar magnitude as for salmon, but even more rapidly. The production has increased, but production in 2008 is at 116,000, which compares to almost two million tonnes of salmon. The difference is primarily demand growth. Sea bass is primarily marketed as portion-sized fish at 300-500 grams. This is small relative to salmon, but has the advantage that turnover in production becomes much higher. As the most valuable of the wild sea bream landed are substantially larger, this has also separated the markets 
for wild and farmed fish. The producers have not succeeded to any extent in expanding the geographical size of the market, as most of the fish is being sold in the EU-countries bordering the Mediterranean. The portion size of the fish is also a limitation on the number of product forms that are marketable. Product development is very limited relative to salmon, despite the fact that sea bass are as accessible to French processors as salmon. The fact that production in recent years (from 2002) has increased without a strong negative price effect is a sign that finally the market is being expanded. In particular, the industry has started producing larger fish, so that it is not restricted to the portion size fish market.

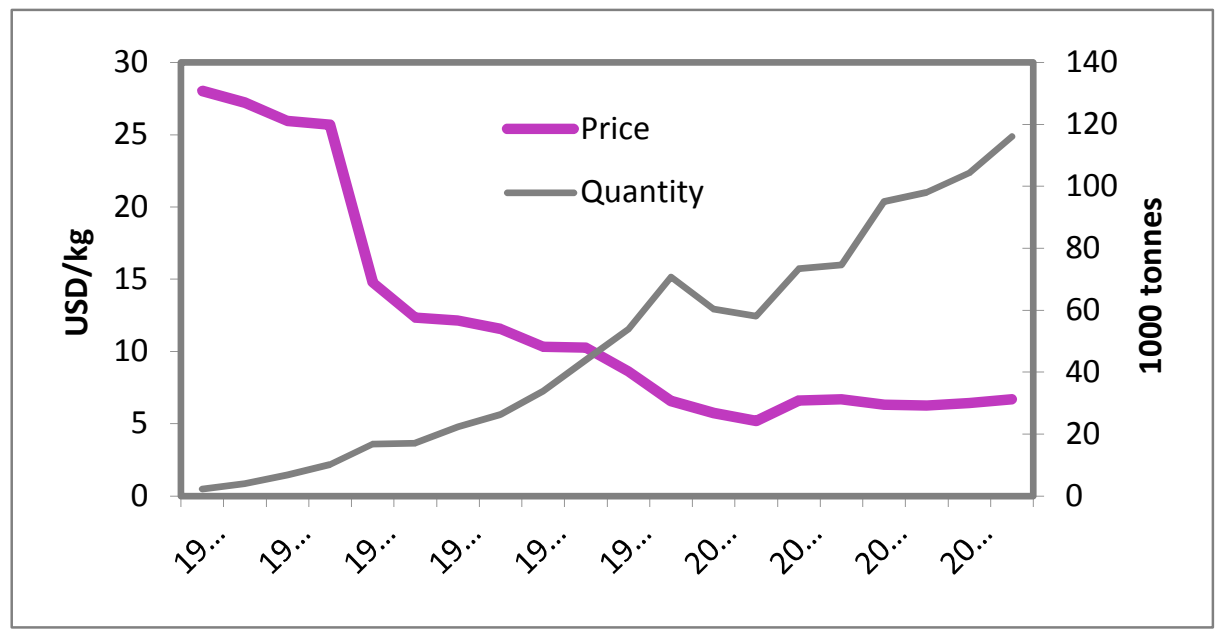

Fig. 4. Real price and global production of sea bass, 1989-2008

\section{Shrimp}

Shrimp is the most valuable farmed species and the seafood species with the highest trade value. Several species are farmed, with white shrimp and black tiger prawns being the most important. Aquaculture production started increasing in the 1970s, and in 2008 was about 3.4 million tonnes. Production growth has, with the exception of the last few years, been slower than for salmon. There have also been more challenges. In particular, there have been several serious diseases, the most serious being the white spot disease. There have also been substantial environmental challenges. These challenges have led to substantial shifts in what have been the most important producer countries [14], and have also led to periods of slower growth as production has been substantially reduced in some regions.

There are several reasons why shrimp aquaculture has faced these challenges. Production technology in shrimp farming is much more diversified than for salmon. It ranges from relatively simple operations where wild caught larvae are placed in crudely dug ponds to sophisticated closed production systems comparable to salmon aquaculture. Moreover, production in many cases takes place on land with little 
economic value (such as mangroves) and poorly defined property rights in countries with no environmental regulations. This has led to environmentally unsound practices in several cases. With high stocking densities, there is high exposure to disease. Moreover, in countries with poor environmental regulations, it may be more profitable to produce with high density for a few years and leave a devastated piece of land than to operate on a sustainable basis. However, technology is steadily improving and best practice producers with closed production systems operate with little risk of disease and in an environmentally sound manner. These sounder practices will most likely win market share, as the scope for technological innovation and productivity growth is highest under such conditions. There are also efforts to promote them in the market place. For instance, the Global Aquaculture Alliance (GAA) is providing certification of good shrimp farming practices.

Farmed shrimp production for 1980 through 2008, along with the price to producers in real US\$ per kilogram, is shown in Figure 5. The average price in 2008 of $4.2 \mathrm{US} \$ / \mathrm{kg}$ is less than half of the price in 1984. Prices stabilised in the mid 1990s when production growth was flat, then declined rapidly after 2000 while production essentially trebled over the next five years. As with salmon, increased production has led to reduced prices. However, the price reduction for shrimp seems to be less than for salmon, up to quite significant volumes. One likely explanation for this is that the supply of wild shrimp is relatively higher, and therefore, there was a large market to win market share from.

As for salmon, shrimp producers have also done well in expanding market size in geographical as well as product space. The market has become global, and the number of product forms has vastly expanded. This has to some extent also been fuelled by trade issues with the USA taking the lead, as anti-dumping tariffs have been imposed on some unprocessed product forms from some countries.

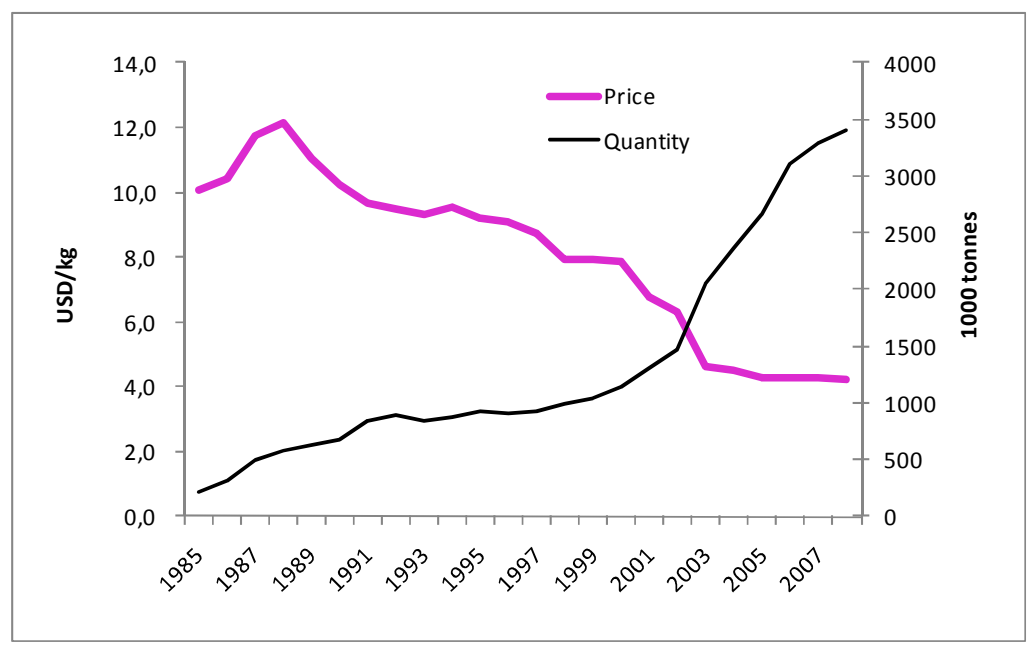

Fig. 5. Real US import price and global production of farmed shrimp, 1985-2008 


\section{Conclusions}

Aquaculture has during the previous two decades been the world's fastest growing production technology. This blue revolution has been possible because increased control with the production technology created condition allowing productivity growth not only in the production, but also through the whole supply chain due to improved logistics, distribution, processing and product development [15]. This has created the demand growth necessary to allow a rapidly increased production to be sold at profitable prices.

We have in this paper reviewed three cases. Salmon has the smoothest productivity growth, but since the mid 1990s, demand growth has been equally important in explaining the growth of the quantity produced. Production increase for shrimp halted in the 1990s when disease problems prevented productivity growth, but has again picked up as these were solved. Sea bass operates at much lower quantities than salmon and shrimp because there have been no marketing innovations creating demand growth, and the whole productivity growth is taken out as lower prices by pumping more fish into the same markets. The price development is similar for all aquaculture species [16], and the quantity development therefore is largely determined by the factors discussed for these three species.

Acknowledgments. The authors would like to thank the Norwegian Seafood Council and the Norwegian Seafood Research Fund for financial support.

\section{References}

1. Smith, M.D., Roheim, C.A., Crowder, L.B., Halpern, B.S., Turnipseed, M., Anderson, J.L., Asche, F., Bourillón, L., Guttormsen, A.G., Kahn, A., Liguori, L.A., McNevin, A., O'Connor, M., Squires, D., Tyedemers, P., Brownstein, C., Carden, K., Klinger, D., Sagarin, R., Selkoe, K.A.: Sustainability and Global Seafood. Science 327, 784-786 (2010)

2. FAO, The state of world fisheries and aquaculture 2010. FAO, Rome (2010)

3. Asche, F., Bjørndal, T.: The Economics of Salmon Aquaculture. Blackwell, Oxford (2011)

4. Asche, F.: Farming the Sea. Marine Resource Economics 23, 507-527 (2008)

5. Asche, F., Roll, K.H., Trollvik, T.: New Aquaculture Species - The Whitefish Market. Aquaculture Economics and Management 13, 76-93 (2009)

6. Asche, F.: Trade Disputes and Productivity Gains: The Curse of Farmed Salmon Production? Marine Resource Economics 12, 67-73 (1997)

7. Tveterås, R.: Flexible panel data models for risky production technologies with an application to salmon aquaculture. Econometric Reviews 19, 367-389 (2000)

8. Guttormsen, A.G.: Input Factor Substitutability in Salmon Aquaculture. Marine Resource Economics 17, 91-102 (2002)

9. Asche, F., Roll, K.H., Tveteras, R.: Economic Inefficiency and Environmental impact: An application to Aquaculture Production. Journal of Environmental Economics and Management 58, 93-105 (2009)

10. Asche, F., Dahl, R.E., Gordon, D.V., Trollvik, T., Aandal, P.: Demand growth for salmon in the European market. Marine Resource Economics 26(4), 255-265 (2011) 
11. Marsh, J.M.: Impacts of Declining U.S. Retail Beef Demand on Farm-Level Beef Prices and Production. American Journal of Agricultural Economics 85, 902-913 (2003)

12. Aasheim, L.J., Dahl, R.E., Kumbhakar, S.C., Oglend, A., Tveteras, R.: Are Prices or Biology Driving the Short-Term Supply of Farmed Salmon? Marine Resource Economics 26, 343-357 (2011)

13. Oglend, A., Sikveland, M.: The Behaviour of Salmon Price Volatility. Marine Resource Economics 23(4), 507-526

14. Anderson: The International Seafood Trade. Woodhead Publishing, Cambridge (2003)

15. Asche, F., Roll, K.H., Tveteras, R.: Productivity Growth in the Supply Chain - Another Source of Competitiveness for Aquaculture. Marine Resource Economics 22, 329-334 (2007)

16. Tveterås, S., Asche, F., Bellemare, M.F., Smith, M.D., Guttormsen, A.G., Lem, A., Lien, K., Vannuccini, S.: Fish Is Food - The FAO's Fish Price Index. PLoS One 7(5), e36731 (2012), doi:10.1371/journal.pone.0036731 